\title{
Perú 2013: LA PARAdOJA de la estabilidad*
}

\author{
Peru 2013: The Paradox of Stability
}

\section{RODRIGO BARRENECHEA}

Northwestern University

\section{PAOLO SOSA VILLAGARCIA}

Pontificia Universidad Católica del Perú

Instituto de Estudios Peruanos

\begin{abstract}
RESUMEN
Este artículo es una revisión del devenir político peruano durante el 2013. El Perú es una democracia sin partidos sostenida en un Estado débil, lo que si bien limita la capacidad de los políticos para establecer vínculos estables con la ciudadanía, no ha afectado seriamente la estabilidad del régimen político. Por un lado, una élite política desprestigiada, precaria y fragmentada coexiste con una influyente tecnocracia económica, fortalecida por los buenos resultados económicos del país en los últimos años. Por otro, esta brecha entre Estado y sociedad hace que la sorprendente (y precaria) estabilidad peruana coexista con signos de descontento entre sectores urbanos que rechazan el sistema político y se ven asediados por la inseguridad ciudadana, mientras que en zonas rurales se registren fragmentados episodios de movilización que dan cuenta de la contracara del crecimiento económico, sostenido en la extracción y exportación de materias primas.
\end{abstract}

Palabras clave: Perú, democracia, conflictos sociales, elecciones, partidos políticos.

\begin{abstract}
This paper is a review of the main political events of 2013 in Peruvian politics. Peru is a democracy without parties sustained in a weak state, which limits the capacity of politicians to establish stable linkages with citizens, but has not had serious consequences for the stability of the political regime. On the one hand, this discredited, fragile and fragmented political elite coexists with an influential economic technocracy, strengthened by the good economy performance of recent years. On the other, this gap separating state and society makes the surprising (and precarious) Peruvian stability coexist with signs of discontent among urban sectors which reject the political system and are besieged by insecurity; while, the existence of fragmented episodes of mobilization in rural areas show the flipside of economic growth sustained in the boom of commodities.
\end{abstract}

Key words: Peru, democracy, social conflicts, elections, political parties. 


\section{INTRODUCCIÓN}

El gobierno de Ollanta Humala, igual que los de Toledo y García en su momento, enfrenta una brecha entre Estado y sociedad (Tanaka y Vera, 2007; Meléndez y León, 2010) que descansa en un sistema de representación política poco enraizado en la sociedad y carente de legitimidad, sumado a un Estado de baja profesionalización e insuficiente presencia en el territorio (Dargent y Muñoz, 2012; Meléndez y Sosa, 2013). Esta situación coexiste con un crecimiento económico sostenido, que si bien ayuda a apuntalar a nuestra precaria democracia, genera tensiones que esta brecha hace difícil resolver. Con sus propias particularidades, el gobierno de Humala viene siendo un capítulo más en la historia de la democracia que siguió a la caída de Fujimori. ${ }^{1}$ En ese sentido, las continuidades han sido mayores que las rupturas. Si el tiempo está compuesto de años que hacen historia y años que son parte de la historia, el 2013 corresponde a este segundo grupo.

En el año que acabó, la precariedad de los partidos políticos y de la élite gobernante se reflejaron en diversas arenas. En el Congreso de la República la fragmentación de las bancadas parlamentarias ha continuado, lo mismo que el desprestigio que padece esta institución ante la ciudadanía. En el Poder Ejecutivo, compuesto por figuras independientes, persiste la imagen de debilidad en la presidencia del Consejo de Ministros, acrecentada por el aparente poder informal de Nadine Heredia ${ }^{2}$ y de la tecnocracia económica, aislada del clima de inestabilidad que caracteriza a nuestro sistema político. La sorprendente permanencia es, en buena cuenta, la característica representativa de este periodo (Vergara, 2013). Este año, la continuidad de Luis Miguel Castilla en el Ministerio de Economía y Finanzas es la más reciente muestra de esa tendencia.

Mientras esta precaria estabilidad se da en las alturas del sistema político, la sociedad continúa manifestando signos de descontento. En las ciudades, las encuestas de opinión continúan recogiendo altas cifras de rechazo al sistema político y una gran preocupación por la inseguridad ciudadana. En el campo, fragmentados episodios de movilización dan cuenta de la contracara del crecimiento económico, sostenido en la extracción y exportación de materias primas. Precisamente, acaso la razón por la que esta brecha entre Estado y sociedad no se ha manifestado de forma más perversa durante este y anteriores años es que el continuo crecimiento económico ha ofrecido condiciones mínimas de estabilidad (Vergara, 2013). En un país con instituciones políticas precarias, el Presidente y las élites políticas en general pueden conducir el país en "piloto automático" solo en tanto la marea se encuentre calma (Meléndez y Sosa, 2013). Como señala Eduardo Dargent (2013), en condiciones externas menos favorables, cuando el actual ciclo de crecimiento llegue a su fin, los desafíos del Perú serán más evidentes. Por ahora, el 2013 fue un año en que el velero navegó con viento a favor.

1 Julio Cotler, por ejemplo, ha usado el término "post-Fujimori" para caracterizar a la sociedad peruana actual. Ver Aragón y Barrenechea, 2012.

2 Nadine Heredia es la primera dama de la nación y presidenta del Partido Nacionalista Peruano. 
El año político 2013 inició en abril con el fin del intento de revocatoria contra la alcaldesa de Lima, Susana Villarán, que tuvo una cobertura mediática sin precedentes en este tipo de procesos $^{3}$. Es precisamente en ese periodo que las cifras de aprobación del presidente Ollanta Humala experimentaron el inicio de una caída significativa: tras empezar el año con 53\% de aprobación en enero, pasó por un rápido y precipitado descenso, para terminar el año con $29 \%$ en diciembre. Una primera lectura de estas cifras puede hacerse desde la coyuntura en la que sucede este descenso. Aunque es complejo determinar su efecto sobre la aprobación, pueden señalarse algunos hechos que pudieron marcar la imagen presidencial.

La caída se inicia en el primer trimestre de 2013 (Gráfico 1), periodo en el que dos temas despertaron la tensión entre el gobierno, la oposición y los medios de comunicación por reflejar un supuesto "chavismo solapado". En primer lugar, la "reelección conyugal", término acuñado por el expresidente aprista Alan García para referirse a la posible candidatura a la presidencia a la primera dama, motivó un debate mediático con la oposición que se prolongó por varios meses con alusiones al modelo "kirchnerista" de sucesión. ${ }^{4}$ La segunda polémica se desarrolló en torno a la intención de compra de grifos y la refinería de Repsol YPF por Petroperú, que se hizo pública, despertando un

Gráfico 1. Aprobación del presidente Ollanta Humala 2011-2013

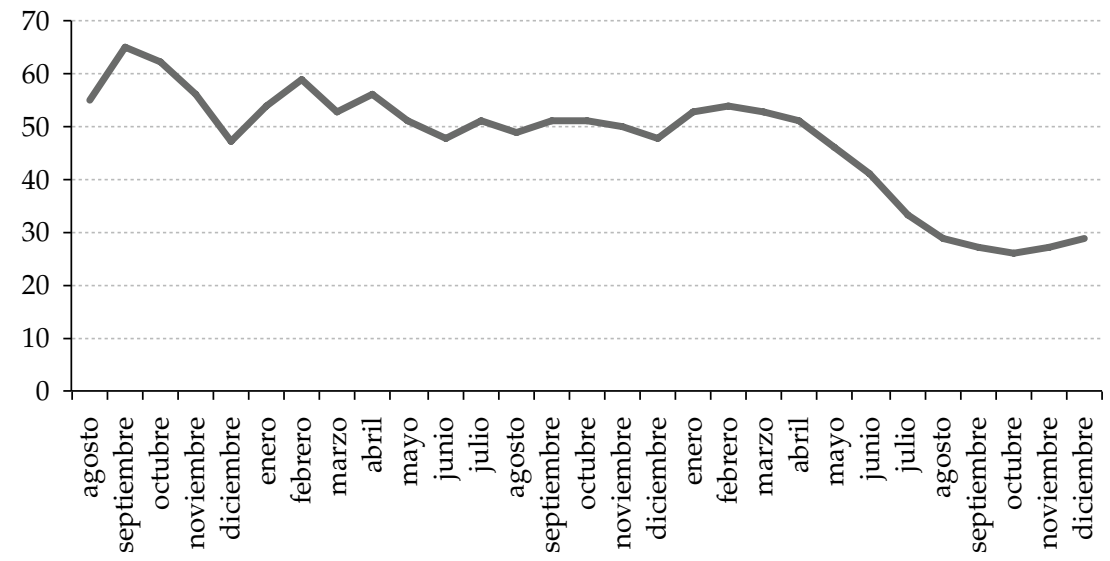

Fuente: Ipsos Perú. Elaboración propia.

3 Martín Tanaka (diario La República, 31/03/14 y 29/12/2014).

4 Como señaló en su momento la Defensoría del Pueblo, este tipo de postulación contraviene la legislación electoral vigente (La República, 14/05/13), sin embargo los comentarios de partidarios del gobierno dejaban abierta la posibilidad de hacer prevalecer el derecho constitucional de la primera dama a participar políticamente como ciudadana peruana. A pesar de la ausencia de acciones concretas que apuntaran en ese sentido, las ambiguas respuestas de la primera dama y del propio Presidente sobre esta posibilidad ofrecieron un espacio para la especulación que fue bien aprovechado por los grupos de oposición y los medios de comunicación. Finalmente, la propia Heredia se encargó de hacer pública su negativa a una posible postulación. "Soy respetuosa de las reglas de juego, estoy negando la posibilidad de la postulación en el 2016", fueron las declaraciones de Nadine Heredia (La República, 05/07/13). 
Gráfico 2: Aprobación presidencial comparada (1995-2013)

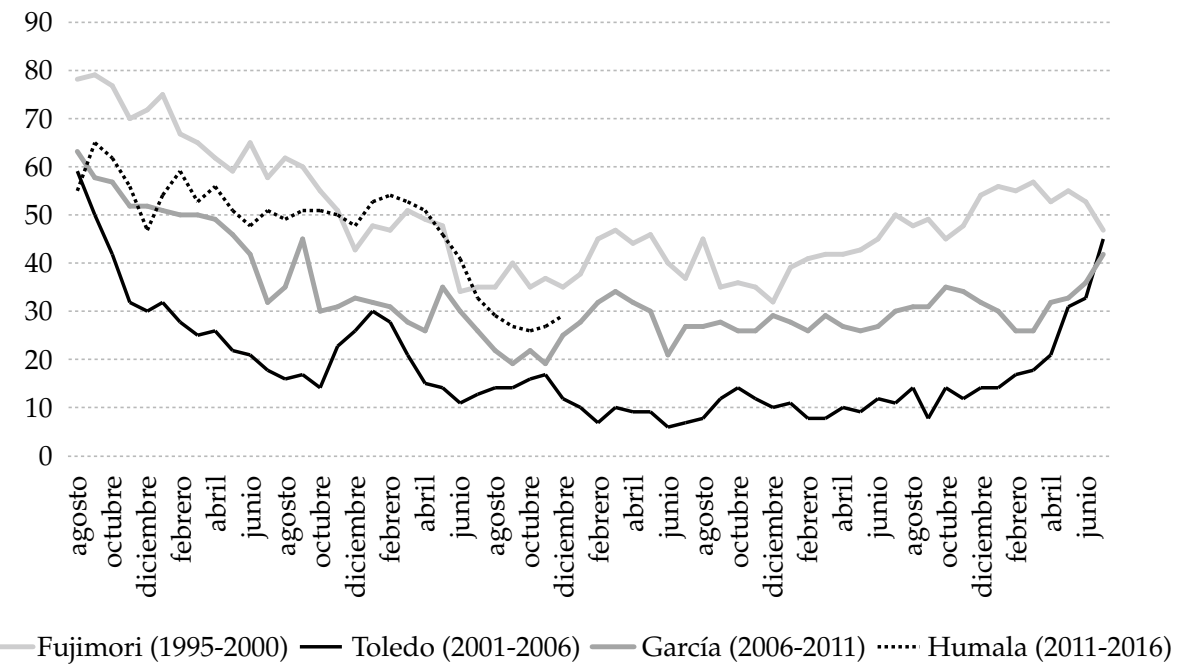

Fuente: Ipsos Perú y Murakami (2013). Elaboración propia.

discurso antiestatista por parte de la oposición, lo que ocasionó que finalmente fuera descartada oficialmente por el gobierno. ${ }^{5}$

A pesar de esta revisión coyuntural, una mirada panorámica rescata dos elementos que nos ayudan a colocar estas cifras de aprobación en perspectiva: la dimensión temporal y la dimensión socioeconómica. Mientras que la primera nos permite entender la tendencia de largo plazo que afectó a los últimos tres presidentes (Humala, García y Toledo), la segunda nos ayuda a resaltar las diferencias que existen en términos de niveles de aprobación al gobierno en los distintos niveles socioeconómicos. Ambas, sostenemos, se encuentran conectadas a la incapacidad de los actores políticos para establecer vínculos estables con la ciudadanía dentro de los parámetros institucionales y estructurales vigentes (ver Tanaka y Vera, 2007; Mainwaring, 2010).

Respecto de la primera dimensión, se observa que desde el retorno a la democracia ha sido muy difícil para los presidentes sostener niveles altos de aprobación, y esto incluye a Ollanta Humala ${ }^{6}$, pues con el descenso registrado en el último año podemos señalar

5 El tema saltó inmediatamente a las portadas de los diarios nacionales, que alertaban un posible retorno al "estatismo" y la intención del gobierno de seguir el modelo de los países "bolivarianos" (ver "5 razones contra el Estado grifero", de Gonzalo Zegarra en Semana Económica, 12/02/13). La activa oposición de los medios y grupos de interés continuó hasta que, nuevamente, las declaraciones de Nadine Heredia pusieron en duda la posibilidad de una compra: "Lo que señaló el presidente (Ollanta Humala) es una intención, un interés, pero si eso no se puede demostrar en los números, que es beneficioso para el país, simplemente no va", señaló la primera dama (Perú 21,30/04/13).

6 Alberto Fujimori fue el último Presidente popular de la historia contemporánea peruana. El ex-Presidente, hoy preso, mantuvo cifras muy altas de aprobación ciudadana, alcanzando incluso el $80 \%$ durante su primer periodo de gobierno (1995-1990). Aunque en su segundo periodo experimentó un descenso importante a partir de 1998, en el contexto de la crisis económica asiática y crecientes demandas de corrupción, el respaldo 
que los niveles de satisfacción ciudadana con la gestión presidencial han "vuelto a la normalidad". ${ }^{7}$ Respecto de la segunda dimensión, las cifras revelan que la insatisfacción ciudadana está distribuida de forma desigual de acuerdo con el estrato socioeconómico del encuestado. Los estratos más bajos demuestran una mayor insatisfacción que los niveles medios y altos, lo que se cumple para todos los presidentes desde el retorno a la democracia.

Una hipótesis a considerar respecto de esta sostenida dificultad para remontar niveles adversos de aprobación presidencial se centra precisamente en la debilidad de los partidos y del Estado. La primera ayuda a explicar la rapidez con la que pueden descender los niveles de aprobación presidenciales; es decir, que no existen identidades políticas sólidas, y por lo tanto las adhesiones pueden cambiar rápidamente. ${ }^{8}$ La segunda ayuda a entender por qué los sectores bajos tienden a ser más críticos de la figura presidencial: son estos los que dependen más claramente de los servicios provistos por el Estado (Mainwaring, 2010).

La brecha que separa a Estado y sociedad en el Perú ha marcado el destino de los últimos presidentes en el Perú, y cerrarla se ha convertido en el principal desafío para la estabilidad de la democracia en el país. En las páginas siguientes haremos un recuento

Gráfico 3: Aprobación presidencial por nivel socioeconómico (promedio anual 2011-2013)

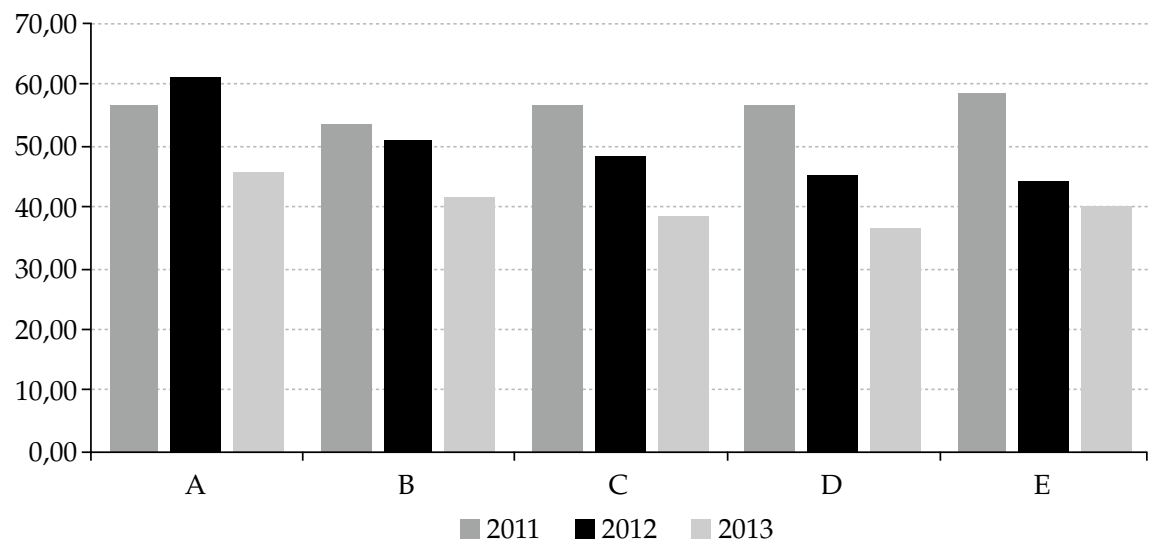

Fuente: Ipsos Perú. Elaboración propia.

con que contaba se mantuvo relativamente alto. Fujimori puso en práctica un sistema de relaciones Estadosociedad que se caracterizó por su verticalidad y por prescindir de intermediarios (Murakami, 2007). Si los partidos eran débiles, utilizó a los medios de comunicación; si hacer uso de las vías regulares del Estado le restaba velocidad y discrecionalidad, entonces utilizaba el "Ministerio de la Presidencia".

7 Los anuarios anteriores (Dargent y Muñoz, 2012; Meléndez y Sosa, 2013) sostienen que la extensión de la "luna de miel" en la aprobación presidencial favorable a la gestión se debió en buena cuenta por medidas concretas y excepcionales como la creación del Ministerio de Desarrollo e Inclusión Social. Sin embargo, como veremos, las características de largo plazo que reseñamos juegan contra Humala, manteniendo la tendencia de sus predecesores.

8 De hecho, según Meléndez (2012a), las principales identidades políticas del país se definen en función al "anti", es decir, en oposición a un grupo político en particular, en este caso el "antiaprismo" y el "antifujimorismo". 
de los hechos políticos más importantes del 2013 en distintos terrenos, para, finalmente, reflexionar sobre su efecto en la calidad de la democracia y el escenario general del sistema político peruano. En ese proceso mantendremos siempre un ojo en el espejo retrovisor, preguntándonos en qué medida lo visto durante este año que pasó representa una ruptura o no con la reproducción de esta brecha.

\section{TEMAS SALIENTES EN LA REALIDAD NACIONAL Y SU IMPACTO POLÍTICO}

\section{Economía}

El crecimiento continuo es uno de los rasgos que ha caracterizado a la economía peruana en la última década. ${ }^{9}$ El Ministerio de Economía y Finanzas, y el Banco Central de Reserva han permanecido desde el inicio del gobierno de Humala bajo el mando de tecnócratas ortodoxos, ajenos a su círculo original representado por economistas cercanos a la izquierda (ver Jiménez, 2012). En un contexto de buenos resultados macroeconómicos, políticos débiles y novatos, y movimientos redistributivos fragmentados frente a organizaciones empresariales, la conducción económica y la continuidad del modelo económico del país ha recaído en una capa de tecnócratas sin adscripción partidaria que ha ganado poder en el Estado (ver Arce, 2010; Vergara, 2013).

Gráfico 4: Variación anual del PBI real 2001-2012 (\%)

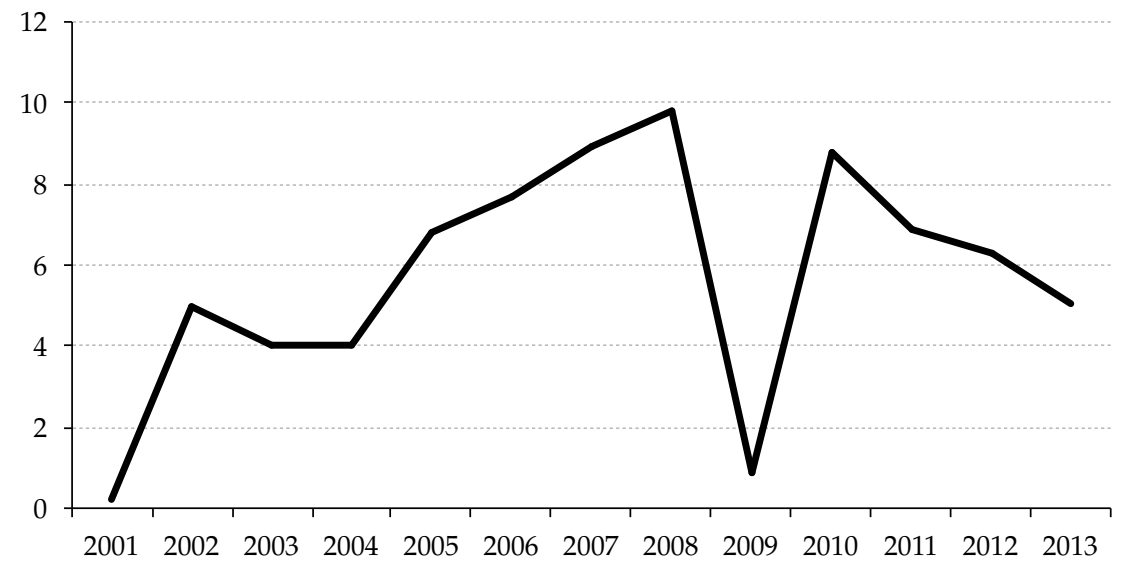

Fuente: BCR. Elaboración propia.

$9 \quad$ Respecto de la fuente del crecimiento, a pesar de la creciente importancia de algunas exportaciones no tradicionales como la agroindustria desarrollada en regiones costeñas, las cifras se sostienen de forma cuantiosa en la exportación de materias primas, en particular minerales (Ghezzi y Gallardo, 2013; Dargent, 2013). El ciclo de incremento de precios en este sector benefició a toda la región y se dejó sentir también en el Perú. La transformación de la estructura productiva es una tarea compleja y que no puede ser evaluada a base de un año de gobierno, sin embargo el 2013 no destaca por el lanzamiento de una sólida iniciativa gubernamental en ese sentido (Grompone, 2013). 
En cuanto a la reducción de la pobreza, el país ha continuado con la disminución de la incidencia de pobreza y pobreza extrema. En 2013 se publicaron las cifras del 2012, en las que el país registra una reducción de $2 \%$, con lo que se acumula una reducción total de 16,6\% en relación con el 2007. Esta disminución ha sucedido en buena cuenta como resultado del crecimiento económico (Ghezzi y Gallardo, 2013); sin embargo se resalta que durante el gobierno de Humala se haya buscado reformar programas sociales de lucha contra la pobreza, de modo que el efecto del crecimiento mismo de la economía se vea acompañado de esfuerzos explícitos y coordinados en esa dirección.

Esta es la principal innovación del gobierno actual mediante un Ministerio de Desarrollo e Inclusión Social (MIDIS) de corte técnico y relativamente autónomo de tentaciones clientelares, a diferencia de la década fujimorista, aunque con importantes réditos políticos para el gobierno (Dargent y Muñoz, 2012; Meléndez y Sosa, 2013). No obstante, parece existir una distancia entre el diseño de la política y su implementación. Por un lado, los programas sociales más cercanos al "modelo clásico" como Pensión 65 y Beca 18 han sido relativamente exitosos, mientras programas más complejos, como Qali Warma, han presentado problemas en la implementación, situación que le ha valido críticas en el 2013. ${ }^{10}$ Por otro lado, la reducción en la cobertura de programas alimentarios por la focalización de los beneficiarios y el proceso de adaptación del nuevo programa no ha generado técnicamente un problema de subcobertura (Aramburú, 2013), pero ha originado problemas entre aquellos grupos que dejaron de ser considerados beneficiarios por los efectos del crecimiento económico, así como por el cambio entre los proveedores por el diseño mismo del nuevo programa y por la priorización de producción local,

Gráfico 5: Perú: Incidencia de la pobreza 2007-2012

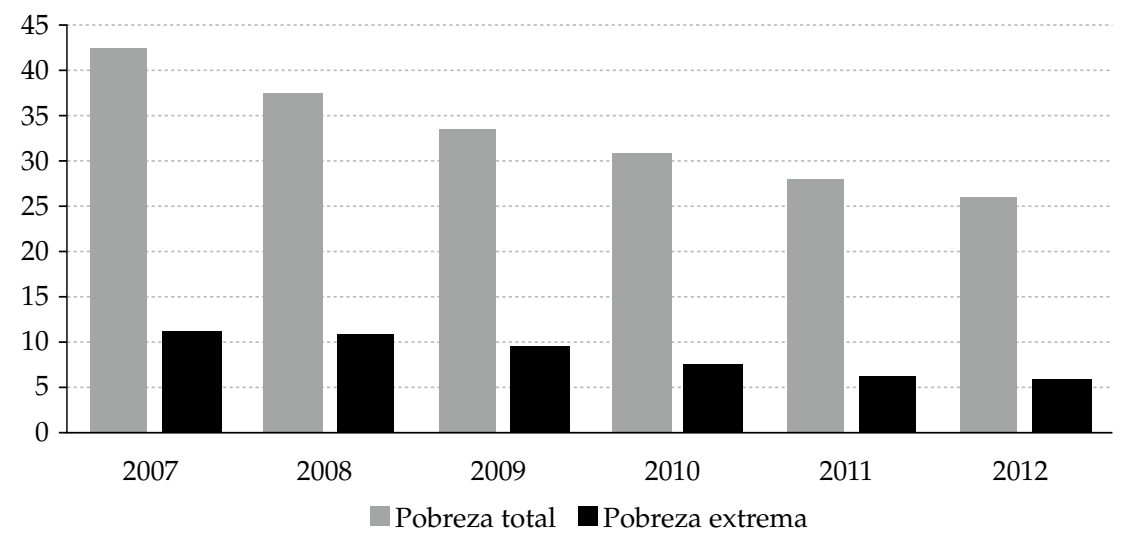

Fuente: MEF. Elaboración propia.

10 Los primeros consisten en programas de asistencia económica, mientras que Qali Warma reemplaza los programas de desayunos escolares y asistencia alimentaria para implementar un programa complejo que involucra componentes nutricionales, organización social, producción local y un enfoque intercultural (para una aproximación integral ver Bregaglio, Chávez y Arévalo, 2013). 
sumando grupos razonablemente interesados en oponerse y resaltar los problemas del actual modelo. ${ }^{11}$

\section{Conflictividad social}

La conflictividad social ha sido la contracara del crecimiento económico peruano en los últimos años y el 2013 no ha sido la excepción a esa tendencia. Una parte importante de estos conflictos tienen como escenario a zonas rurales o ciudades intermedias con vínculos importantes con zonas rurales. La expansión de actividades extractivas, particularmente de la minería, ha generado transformaciones sociales y tensiones que han derivado en una presencia constante aunque desarticulada de episodios de movilización social (ver Bebbington, 2013). Según los reportes mensuales de la Defensoría del Pueblo, el año inició con 158 conflictos sociales activos en el mes de enero, y culminó con 174. Aunque desde este punto de vista las cifras sugieren un relativo incremento, este no parece demasiado significativo si se observan los datos anuales (Gráfico 6). Comparando el número de conflictos con los registrados el 2009, año en que estos alcanzaron 235 en el mes de julio, la situación parece haberse estabilizado en una meseta que hace de los conflictos un fenómeno constante, pero de poca relevancia nacional.

La dinámica política en la conflictividad social ha comprometido a redes sociales formadas sobre la base de estructuras de organización previas como las rondas campesinas, pese a ello, estas no han podido articular un movimiento nacional (Meléndez, 2012b),

Gráfico 6: Número de conflictos sociales activos 2009-2013

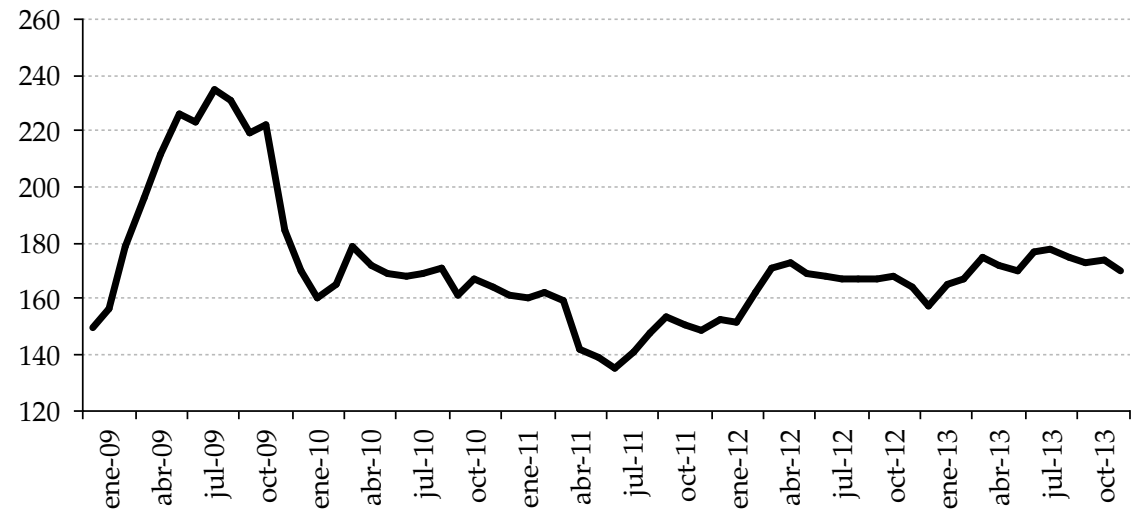

Fuente: Defensoría del Pueblo. Elaboración propia.

11 El gran reto de estos programas es operar en un contexto de debilidad estatal para supervisar la calidad de los productos y el cuidado de los encargados; así como la politización de estos problemas, ya sea por los problemas intrínsecos o a comparación de otros programas sociales (ver Trivelli, 2014). Sobre el programa Juntos se puede ver Correa y Roopnaraine, 2013. 
característica con marcadas raíces históricas. ${ }^{12}$ Por otro lado, el gobierno actual desarrolló dos reformas importantes en la gestión de la conflictividad social: la aprobación de una ley y reglamento sobre la consulta previa a pueblos indígenas y originarios, y la transformación de la Oficina de Gestión de Conflictos Sociales en la Oficina Nacional de Diálogo y Sostenibilidad. Sin embargo, a pesar del optimismo inicial y los importantes esfuerzos burocráticos, ${ }^{13}$ a la fecha estas reformas parecen no haber impactado políticamente de la forma en que se esperaba especialmente desde la perspectiva de la sociedad.

Por un lado, la ONDS sigue marcada por una lógica tecnocrática manejada por figuras independientes, lo que revela una concepción burocrática de los conflictos sociales (ver Bedoya, 2013). ${ }^{14}$ El Partido Nacionalista parece no estar interesado o ser incapaz de penetrar políticamente aquellos espacios en los cuales se gestan las movilizaciones y el descontento con el gobierno, ya sea para establecer pactos con los actores movilizados o para arrinconarlos políticamente. Por otro lado, la consulta previa, iniciativa mucho más ambiciosa, es vista como inoperante y estancada desde diferentes lados del espectro político. ${ }^{15}$ Los cambios en la coyuntura económica y la falta de una coalición política y social capaz de apoyar la medida generan un incremento en el costo político de esta política. Esta situación aprovecha el diseño institucional, caracterizado por la debilidad del sector encargado de su implementación y la fragmentación de responsabilidades entre agencias estatales, para favorecer la preeminencia de sectores como Energía y Minas en su negativa a la implementación de la medida. ${ }^{16}$

Como puede verse en ambas iniciativas, el vínculo entre sistema político y sociedad permanece quebrado. Si bien resalta una disminución en las tensiones a comparación del gobierno aprista, el análisis que se sigue desde los últimos anuarios resalta que la estabilidad peruana se sostiene en un equilibrio de baja intensidad sobre la base de una

12 La politización rural durante los años setenta y ochenta se vio favorecida por el proceso de reforma agraria que, si bien resultó en un proceso de desarrollo organizativo trunco y fue menos profundo que países como Ecuador o Bolivia (Yashar, 2005), sí sentó bases importantes para la articulación del campo a partidos de izquierda durante esas décadas (Contreras, Paredes y Thorp, 2011). Sin embargo, este proceso se vio golpeado de forma notable como resultado del desarrollo de las actividades de Sendero Luminoso en el campo, pérdida que se vio contrarrestada solo parcialmente por el fortalecimiento de las Rondas Campesinas durante el gobierno de Fujimori (ver Degregori et al., 1996; Paredes, 2010). Este deterioro organizativo se vio acompañado por un proceso de "clientelización" en el que Fujimori estableció un modelo de relación vertical y sin intermediarios, en el que el Presidente se vinculaba directamente con las bases, por lo que no fortaleció liderazgos intermedios ni dejó una organización estable tras de sí (ver Puémape, 2013).

13 Ver, por ejemplo, la propuesta integral de la mediación de conflictos sociales de la ONDS, 2013.

14 Vladimiro Huaroc, funcionario al frente de la ONDS fue nombrado en el cargo en 2012, y despertó expectativas sobre su gestión en tanto se trataba de un personaje con perfil político, proveniente de la tradición de izquierda en el país, pero que en los últimos años se había desempeñado en cargos de elección popular sin pertenecer a ninguna organización política, por lo que su nombramiento no supone una relación con el partido de gobierno (ver Navarro, 2013).

15 Para los sectores vinculados a la izquierda, incluyendo algunas organizaciones indígenas, la consulta previa, tal cual ha sido concebida en la legislación peruana, representa un formalismo sin mayor posibilidad de influencia, especialmente en términos de concesiones mineras. Por otro lado, los sectores empresariales y conservadores ven a la consulta previa como una "traba burocrática" que impide el desarrollo de la inversión privada (ver Gálvez y Sosa, 2013).

16 El sector encargado es el Ministerio de Cultura por medio de su Viceministerio de Interculturalidad. En lo que va del gobierno, este sector ha cambiado de ministro tres veces y de viceministro cuatro veces en escenarios de tensión importantes (ver Gálvez y Sosa, 2013). 
fragmentación de organizaciones sociales, incapaces de movilizarse masiva y sistemáticamente frente al Estado, así como las fallas del sistema político en su intento por penetrar la sociedad. Esta situación continúa priorizando la resolución ad hoc de los conflictos sociales y la importancia política de algunos sectores (MEF, MEM) dentro del Estado. ${ }^{17}$

\section{Seguridad pública}

La sensación de inseguridad viene creciendo en el Perú en los últimos años. A medida que el desempleo se ha ido rezagando en las encuestas como la principal problemática que aqueja a los ciudadanos, la inseguridad ha ido cobrando prioridad. El último informe del Latinobarómetro (2013) coloca al Perú en el tercer lugar en percepción de inseguridad en la región, detrás de Venezuela y Uruguay. La incapacidad para dar solución a los problemas de inseguridad ciudadana es uno de los principales desaciertos que se le atribuyen al gobierno de Humala (ver Gráfico 7).

Durante el 2013 el Ministerio del Interior sufrió un cambio de titular. En noviembre fue relevado del cargo Wilfredo Pedraza, quien venía ejerciéndolo desde julio de 2012, y este fue asumido por Walter Albán, quien, como ha sido la tendencia en el gobierno de Humala, no forma parte del Partido Nacionalista ni de la coalición de gobierno. ${ }^{18}$ El reemplazo de Pedraza se dio luego de que una investigación periodística descubriera que

Gráfico 7: Principales desaciertos del gobierno actual (julio 2013)

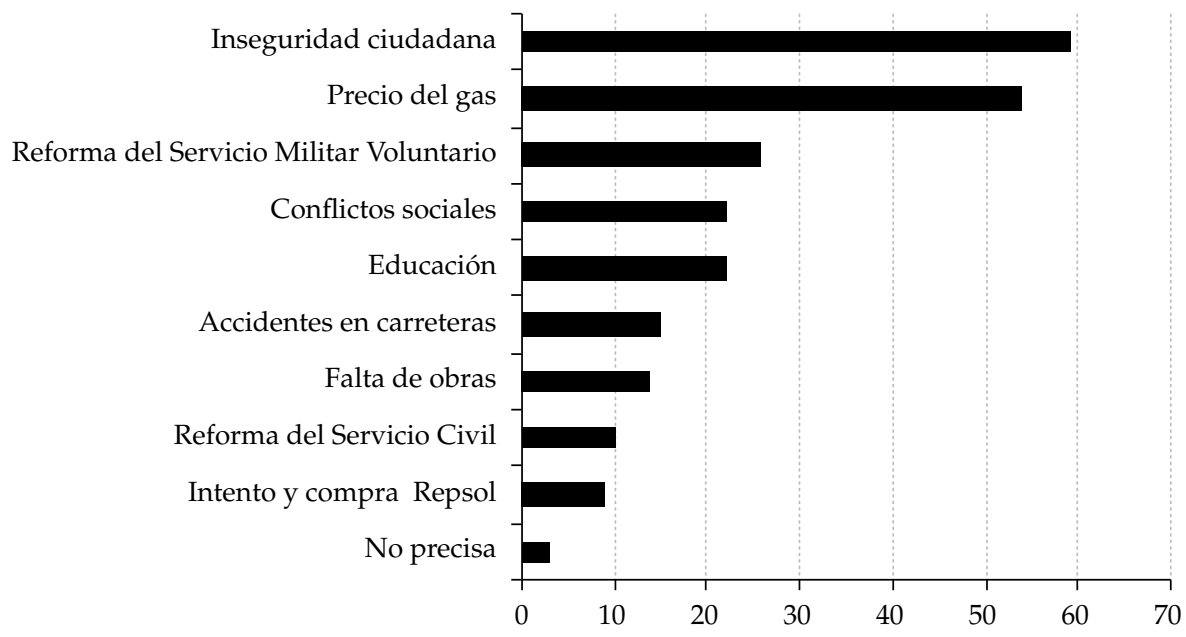

Fuente: Ipsos Perú. Elaboración propia.

17 Sin embargo, estudios como Arce (2014) o los compilados en Bebbington (2013) señalan que a pesar de la localidad y fragmentación de estos conflictos, estos han logrado establecer cambios paulatinos en algunos sectores.

18 Se trata de un jurista independiente que destacó por su labor a la cabeza de la Defensoría del Pueblo tras la caída del gobierno de Alberto Fujimori. Hasta antes de su nombramiento se desempeñaba como embajador peruano ante la Organización de Estados Americanos. Su nombramiento fue criticado por la oposición debido a su falta de experiencia en el campo de la seguridad ciudadana. 
la Policía Nacional (PNP) ofrecía resguardo de forma irregular a la vivienda del ciudadano Oscar López Meneses, procesado por sus vínculos con el exasesor de inteligencia de Alberto Fujimori, Vladimiro Montesinos. ${ }^{19}$ Esta denuncia motivó que el presidente Humala hiciera un enfático deslinde con el "montesinismo", y que renunciara no solo el ministro Pedraza, sino el asesor presidencial en temas de seguridad Adrián Villafuerte. ${ }^{20}$

La renuncia de importantes personajes en el gobierno y el aún no esclarecido resguardo a López Meneses resaltan el carácter poco transparente de la PNP y las FF.AA., así como los aparentes vínculos que algunos sectores afines al gobierno de Fujimori todavía mantienen en ambas instituciones. ${ }^{21}$ La herencia de debilidad y poca transparencia de ambas instituciones se observa no solo en episodios como el de López Meneses, sino también en el hecho de que el puesto de titular del Ministerio del Interior ha sido uno de los más inestables desde el retorno a la democracia. Escándalos de corrupción o de ineficacia policial han sido las causas más comunes de estos cambios, el 2013 ha agregado un año más a esta tendencia de largo plazo (Rospigliosi, 2013).

\section{El caso Fujimori}

Desde que el expresidente Alberto Fujimori fue sentenciado en mayo de 2009 a 25 años de prisión por delitos de Lesa Humanidad, la posibilidad de un indulto humanitario ha estado presente de forma constante en la agenda pública. En octubre de 2012 el indulto fue solicitado por los hijos del ex-Presidente, incluidos el actual congresista Kenji Fujimori y la excandidata presidencial Keiko Fujimori. Luego de varios meses de espera, el presidente Humala finalmente rechazó la solicitud en junio de 2013, alegando que no existían razones médicas suficientes para tomar esa decisión.

La posibilidad de que Humala concediera el indulto se mantuvo latente en la opinión pública en los meses que transcurrieron entre la solicitud y su rechazo. Existían razones para ello. Por un lado, la paulatina descomposición de la bancada de Alianza Parlamentaria, aliada de facto del gobierno y liderada por el partido del expresidente Alejandro Toledo, hacía posible que el gobierno buscase un aliado sólido como el fujimorismo que le otorgase mayoría en el Congreso (ver Tabla 2). ${ }^{22}$ Por otro, las pérdidas para el gobierno en términos de popularidad no parecían del todo claras. Fujimori es

19 López Meneses ha sido señalado por la prensa como uno de los operadores de Montesinos en el Congreso de la República, y como uno de sus más cercanos colaboradores en general.

20 Villafuerte era considerado uno de los hombres de mayor confianza de Humala desde el inicio de su mandato, y había sido cuestionado por haber trabajado en el pasado como edecán del exgeneral del Ejército peruano César Saucedo, quien fue detenido por actos de corrupción luego de la caída de Alberto Fujimori.

21 El proyecto autoritario de Fujimori no solo supuso la eliminación de contrapesos, sino también el control político del aparato represivo, pasando a un segundo plano la dimensión meritocrática y profesional de las fuerzas armadas y policiales. Coincidentemente, es probable que fueran estas dos instituciones, junto al Poder Judicial y el Congreso de la República, las que más se debilitaron durante los años noventa (ver Mora et al., 2001).

22 Luego de que Alianza Parlamentaria pasara de 20 integrantes en 2011 a 10 en 2013, la idea de contar con un aliado sólido y cohesionado como el fujimorismo no resultaba despreciable. A ello debía agregarse que la propia bancada de gobierno había reducido su número debido a la escisión de algunos parlamentarios que consideraron que Humala había traicionado su plan de gobierno original. 
Gráfico 8: Percepción popular sobre el pedido de indulto para Alberto Fujimori

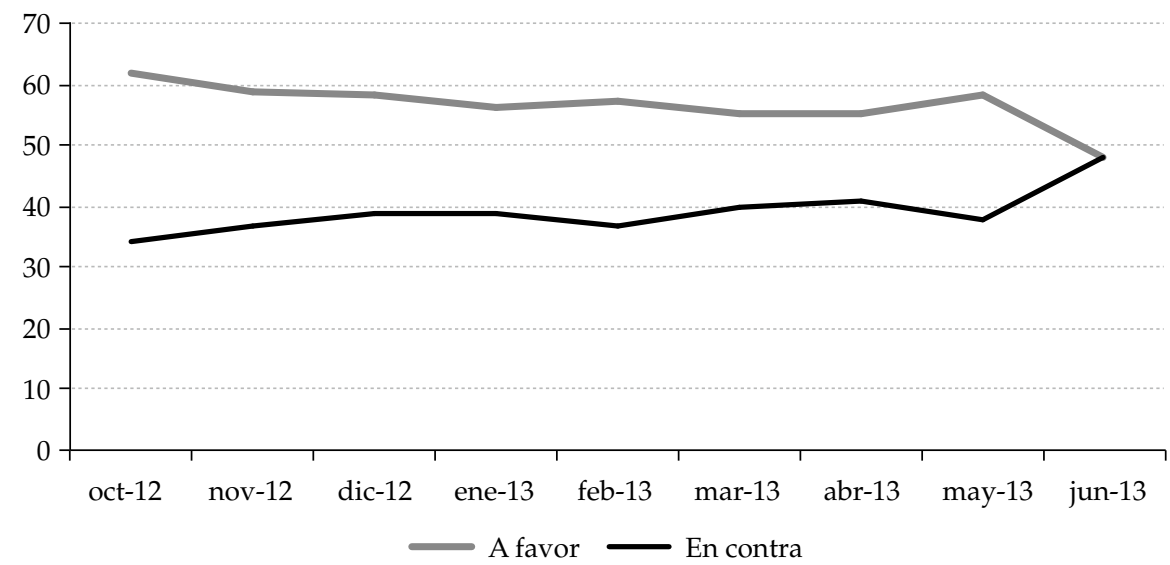

Fuente: Ipsos Perú. Elaboración propia.

todavía un personaje popular para amplios sectores del país. ${ }^{23}$ En las semanas finales, sin embargo, la campaña a favor del indulto cometió importantes errores que pueden haber inclinado la balanza en contra del ex-Presidente. Aunque la bancada fujimorista, sus abogados y médicos se esforzaban por mostrar la imagen de un Fujimori convaleciente, la filtración de fotografías y videos que mostraban a un Fujimori vital y en buenas condiciones en su permanencia carceleria parecían contradecir esta idea.

En todo caso, más importantes que las causas del rechazo al indulto han sido sus consecuencias. Desde junio de 2013 Fujimori ha incrementado sus comunicaciones públicas y ha elevado su perfil político, criticando las políticas y decisiones del presidente Humala. Mediante redes sociales, cartas y llamadas no autorizadas a medios de comunicación, Fujimori ya no solo reclamaba por su inocencia sino que reclamaba su vigencia política con el ejercicio de un rol de oposición política al gobierno. Las posibilidades con que cuenta Fujimori para hacer llegar sus puntos de vista y demandas a los medios de comunicación han llamado la atención sobre sus privilegiadas condiciones carcelerías. Sin embargo, estas son solo un reflejo del poder con que aún cuenta el fujimorismo en la sociedad y política peruana.

\section{COYUNTURA SUBREGIONAL E INTERNACIONAL}

El 2013 estuvo marcado en el ámbito internacional por la expectativa que generó el fallo de la Corte de La Haya en torno a la controversia limítrofe que el Perú sostenía con 
Chile. ${ }^{24}$ Aunque se esperaba que la lectura de sentencia se dé en el último trimestre del año, en septiembre la Corte anunció que esta se daría recién en el mes de enero de 2014. Entre la clase política destacó el pedido de unidad que hizo el presidente Humala a los diferentes líderes de oposición, a quienes se solicitó no adelantar ni dar evaluaciones del fallo antes de escuchar la posición oficial de la presidencia. ${ }^{25}$

El fallo de la Corte estableció que el límite marítimo con Chile quedaba determinado por una línea paralela que iniciaba en el hito 1 de la frontera terrestre entre ambos países, como planteaba la posición chilena. Sin embargo, esta línea se extendía solo hasta las 80 millas, luego de las cuales la frontera se extiende a lo largo de una línea equidistante a ambos países, lo que recoge parte de la pretensión peruana (ICJ, 2014). En el balance final, el gobierno peruano anunció este fallo como una victoria, en tanto se le reconoció al país casi 50.000 kilómetros cuadrados de mar, más del 70\% de lo que se había demandado ante la Corte. ${ }^{26}$

Finalmente, el fallo ha dejado abierta una nueva controversia, aunque esta vez menor. Chile interpreta que el fallo señala que ese país tiene el control soberano de un triángulo terrestre aproximado de 38 mil metros, que va del hito número 1 al punto en que la línea paralela se encuentra con el mar. Por otra parte, la posición peruana es que la sentencia no se refiere a la delimitación terrestre entre ambos países, y que el triángulo terrestre -que contaría con 200 metros de "costa seca"- es considerado parte del territorio peruano. La solución de esta controversia ha quedado como un nuevo tema pendiente entre ambos países.

\section{CAMBIOS INSTITUCIONALES Y CAMBIOS SUBSTANCIALES EN POLÍTICAS PÚBLICAS}

Si algo ha caracterizado el 2013 ha sido el intento de introducir reformas en diferentes sectores y el consecuente rechazo de la ciudadanía, grupos de presión, u organizaciones gubernamentales autónomas como la Defensoría del Pueblo. La ausencia de coaliciones políticas o sociales que acompañen estas iniciativas ha limitado sus posibilidades de

24 Durante este año, el canciller Roncagliolo debió soportar la presión de quienes solicitaban su remoción del cargo debido a un supuesto manejo deficiente de la cartera en temas no relacionados con la demanda marítima. Sin embargo, la expectativa ante el fallo en La Haya hizo que fuera muy complejo para la oposición conseguir los votos e interpelar al ministro en el Congreso. Finalmente, Roncagliolo renunció en mayo por motivos de salud, dejando el cargo en manos de Edda Rivas, quien hasta entonces se había desempeñado como ministra de Justicia.

25 Pese a ello, en los días previos y posteriores al fallo, el expresidente Alan García tuvo un papel protagónico en términos de declaraciones públicas y apariciones en medios de comunicación, haciendo incluso un llamado a embanderar viviendas a nivel nacional. Capitalizar políticamente el fallo pareció ser el objetivo de García, de quien se piensa postulará a la presidencia el 2016.

26 Entre la población peruana, la sentencia ha sido recibida favorablemente. De acuerdo con una encuesta nacional urbana publicada por Ipsos-Perú en febrero, 50\% de los entrevistados considera que el resultado ha sido equitativo tanto para ambos países. Por otro lado, 35\% considera que la Corte dio la razón en su mayoría a Perú y $12 \%$ a Chile. 
éxito y ha puesto de manifiesto una vez más la ya mencionada brecha entre el Estado y la sociedad.

Dos de las reformas más importantes han sido la implementación de la Ley del Servicio Civil y la reforma de la Ley Universitaria. La primera iniciativa fue elaborada por la Autoridad Nacional del Servicio Civil (SERVIR) y promulgada en los primeros días de julio con la intención de introducir un sistema meritocrático con mejores incentivos salariales para los funcionarios públicos de acuerdo con los objetivos de la agencia estatal (SERVIR, 2012). ${ }^{27}$ La segunda iniciativa, propuesta en el Congreso, incluye aspectos sustantivos sobre la función, organización y administración de las universidades públicas y privadas. La respuesta opositora a estas reformas ha argumentado insistentemente la falta de diálogo por parte del gobierno y los parlamentarios, señalando que se ha excluido del debate a los sectores directamente involucrados y la existencia de intereses particulares como en el caso de la Ley Universitaria. ${ }^{28}$

Ambas reformas merecieron como respuesta movilizaciones nacionales dirigidas por trabajadores estatales y universitarios, respectivamente. A pesar de sus limitaciones, estos gremios articularon protestas de alcance nacional de mediana incidencia durante los meses de junio y julio. Esta concordancia temporal en las protestas dio una imagen de amenaza a la gobernabilidad, en especial durante las movilizaciones convocadas el 27 y 28 de julio durante la presentación anual del presidente Humala ante el Congreso. La oposición ha intentado capitalizar este descontento sin llegar a proponer alternativas, lo que ha generado que las reformas sigan su curso de implementación a pesar de las protestas como en el caso de la Ley SERVIR o que se dilate el debate como en el caso de la Ley Universitaria. Más allá de estos dos ejemplos, la condición de relativo aislamiento político de las reformas propuestas, a pesar de su naturaleza tecnocrática o la presencia de intereses particulares, es indicativo de nuestro argumento central. ${ }^{29}$

\section{COYUNTURA ELECTORAL: PROCESO DE REVOCATORIA EN LIMA}

Si bien señalamos que el año político 2013 inició con el fin del intento de revocatoria, el resultado de este proceso marcó nuevamente el escenario electoral con un panorama adverso para la izquierda peruana. Si bien se logró evitar que la alcaldesa Susana Villarán (líder del partido "Fuerza Social") fuese revocada, casi la totalidad de los concejales oficialistas no corrieron la misma suerte. El proceso de revocatoria fue el resultado de la confluencia de dos elementos: (1) el relativo aislamiento político e impopularidad de

27 Para ver en detalle los antecedentes y alcances de esta reforma se recomienda revisar Sparch, 2012 y Alza, 2012; para el debate político alrededor de la reforma.

28 Ver "Veinte opiniones sobre el dictamen aprobado de nueva Ley Universitaria", en http://bit.ly/1gSJWVp (Corresponsales, 30/01/14).

29 Una reforma importante expuesta desde el Congreso de la República es el proyecto de ley sobre las uniones civiles entre personas del mismo sexo. Esta medida, propuesta por el congresista Jorge Bruce, ha generado oposición por sectores eclesiales y conservadores, pero ha recibido el visto bueno del Poder Judicial y la Defensoría del Pueblo mediante informes favorables. Su debate en el Congreso está reservado para el presente año. 
un grupo político que se hizo de la alcaldía de forma inesperada; y (2), una oposición muy activa que desde el inicio de la gestión buscó impulsar un proceso de revocatoria (ver Meléndez y Sosa, 2013).

Fuerza Social era un partido relativamente pequeño y desconocido cuando se hicieron de la alcaldía en 2011 con una victoria apretada, sostenida sobre un apoyo ocasional y volátil entre la ciudadanía. ${ }^{30}$ En consecuencia, las cifras de aprobación a la alcaldesa se redujeron drásticamente en pocos meses (ver Gráfico 9). Sin una base sólida de apoyo, las iniciativas de Villarán en la alcaldía, que rompieron con el estilo de su antecesor centrado en grandes obras de infraestructura, tuvieron un alto costo en términos de respaldo ciudadano. ${ }^{31}$ Respecto del segundo punto, los opositores se encontraron principalmente fuera del gobierno municipal. La alcaldesa tuvo que enfrentar la oposición del Partido Aprista Peruano, de medios de comunicación de tendencia conservadora y de poderes fácticos como las autoridades eclesiales; así como la oposición activa de sectores allegados al exalcalde Luis Castañeda. ${ }^{32}$ Precisamente estos sectores fueron los encargados de impulsar el proceso de revocatoria contra la alcaldesa.

\section{Gráfico 9: Aprobación de la alcaldesa de Lima Susana Villarán}

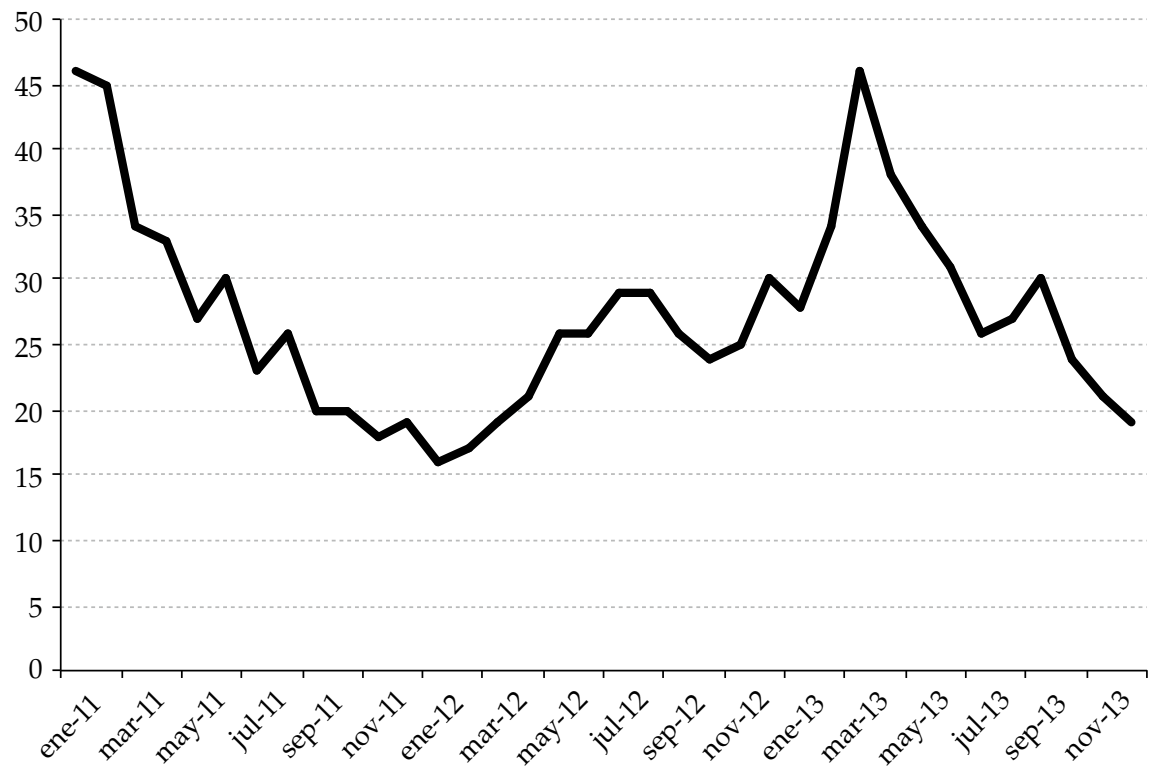

Fuente: Ipsos Perú. Elaboración propia.

30 Su triunfo, inesperado en una ciudad que ha votado siempre por candidatos conservadores desde fines de los ochenta, fue posible gracias al retiro de la candidatura de Álex Kouri, el candidato favorito a ganar esos comicios. Esta candidatura fue retirada tras hacerse objeciones de tipo formal en su inscripción como candidato.

31 Aunque su aprobación se recuperó hasta sus niveles iniciales tras el proceso de revocatoria, este se desplomó nuevamente poco después (ver Gráfico 9).

32 Castañeda se había visto perjudicado en sus aspiraciones presidenciales en 2011 por las revelaciones de una comisión investigadora en el municipio, que puso al descubierto supuestos actos de corrupción en los que el exalcalde habría estado involucrado (Meléndez, 2011: 188-192). 
Gráfico 10: Intención de voto en la revocatoria contra Susana Villarán (2012-2013) 33

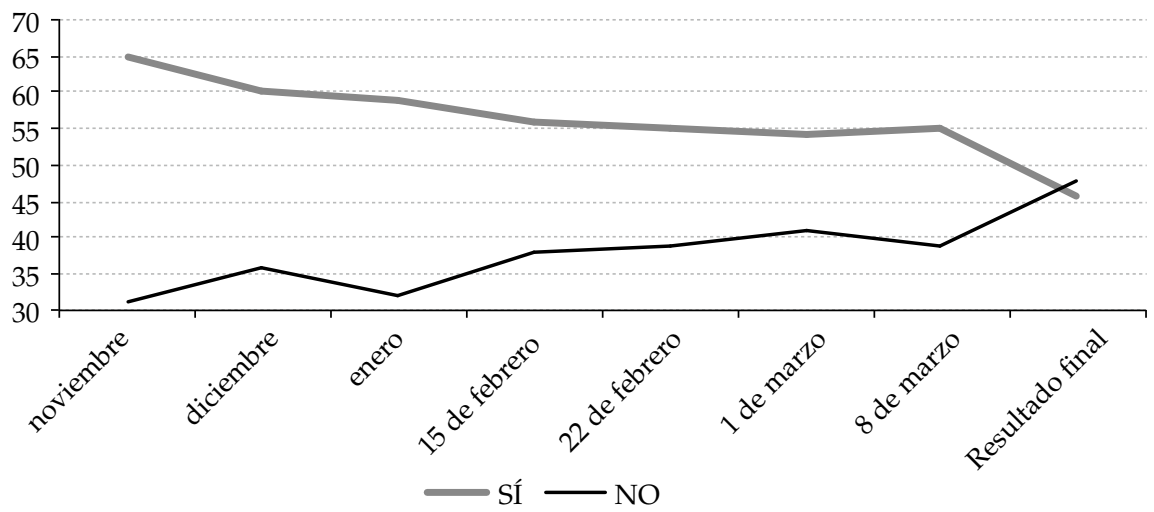

Fuente: Ipsos Perú y ONPE. Elaboración propia.

Finalmente Villarán logró permanecer en el cargo, pero no los regidores oficialistas, quienes fueron revocados casi en su totalidad. Las razones detrás de la recuperación de Villarán en las cifras de intención de voto son difíciles de determinar. ${ }^{34}$ Por un lado, el equipo de campaña de la alcaldesa cambió radicalmente de estrategia a inicios del 2013, luego de la contratación del asesor de campaña Luis Favre. ${ }^{35}$ A partir de ese momento, la campaña se centró en las desventajas y costos asociados a la revocatoria de la alcaldesa, antes que en las ventajas de su permanencia en el cargo. Adicionalmente, cobró relevancia el papel jugado por los impulsores del proceso, y los intereses que estos representaban. ${ }^{36}$ En suma, el resultado final del proceso de revocatoria pareció reflejar más un rechazo a sus opositores y a las consecuencias de la revocatoria, que un respaldo decidido a la gestión de Villarán.

La debilidad de la coalición oficialista fue puesta en evidencia meses después, durante las elecciones complementarias del 24 de noviembre. ${ }^{37}$ La coalición de gobierno logró

33 La opción SÍ representa el apoyo a la revocatoria, la opción NO representa el rechazo. La cifra final en el gráfico representa los resultados oficiales para el caso de Villarán.

34 Como se puede observar (ver Gráfico 10), la recuperación de Villarán se da en las semanas e incluso días inmediatamente anteriores a la fecha de las elecciones, y fue siempre más importante en los niveles socioeconómicos medios y altos. Este fenómeno de apoyo a una gestión de izquierda por parte de sectores socioeconómicos altos y desaprobación en sectores populares llamó la atención de distintos analistas y científicos sociales. Se han ensayado diferentes interpretaciones para este fenómeno (ver Maldonado, 2013).

35 Favre había destacado en el pasado por ser el asesor de Ollanta Humala durante su campaña, y fue considerado pieza clave en su victoria en 2011.

36 De acuerdo con cifras de la encuestadora Ipsos Perú, mientras en enero de 2013 el $62 \%$ de los limeños indicaba que el proceso de revocatoria era resultado de una mala gestión, esta cifra se había reducido a $41 \%$ en marzo. Por el contrario, aquellos que señalaban que este era fruto de intereses políticos, pasaron de representar el $31 \%$ en enero a $48 \%$ en marzo.

37 Estas elecciones se realizaron con el fin de elegir a nuevos concejales, que reemplazarían a aquellos 22 revocados por el proceso de revocatoria desarrollado hacía meses. La coalición liderada por Fuerza Social había perdido 20 del total de 21 concejales que tenía en el concejo municipal, mientras que la oposición perdió a dos, ambos del partido Solidaridad Nacional, del exalcalde Luis Castañeda. 
obtener solo 7,6\% de los votos válidos, lo que se tradujo en la elección de dos concejales. De otro lado, el principal partido de oposición a Villarán dentro del concejo, el Partido Popular Cristiano (PPC), obtuvo el 29,6\% de los votos y pasó de 10 a 17 concejales, ${ }^{38}$ mientras que las restantes 13 posiciones disponibles fueron divididas entre otras cinco listas. Con estos resultados, la oportunidad que de forma inesperada se le abrió a la izquierda en la ciudad de Lima parece cerrarse.

\section{PODER EJECUTIVO}

El Poder Ejecutivo durante el actual periodo de gobierno refleja claramente los efectos de la "democracia sin partidos" peruana. Inestabilidad en los cargos y predominio de figuras independientes son las características básicas que han primado en lo que va del gobierno nacionalista, y el 2013 sigue esta tendencia. En total, han ejercido el cargo de Primer Ministro ${ }^{39}$ cuatro personas en dos años y medio, tres de ellos sin vinculación con la agrupación política del Presidente (ver Tabla 1).

Juan Jiménez, quien había ejercido el cargo desde julio de 2012, fue reemplazado en noviembre del 2013 por César Villanueva, un político con una trayectoria destacada en el ámbito subnacional, pero que no había ejercido cargos nacionales hasta su nombramiento como Premier (ver De Gramont, 2011). Las razones detrás del cambio no fueron evidentes, porque este no sucedió en el contexto de una crisis o circunstancia política extraordinaria. No es exagerado señalar que lo más importante en este cambio en el Ejecutivo fue su casi total falta de consecuencias para la composición del gabinete (ver Tabla 1). Debido a la importancia y responsabilidad con que carga el Presidente del Consejo de Ministros, la composición del gabinete es normalmente resultado de un acuerdo entre este y el Presidente de la República, ${ }_{1}^{40}$ por lo que la ausencia de cambios en el último consejo de ministros dejaba a sospecha que el nuevo Primer Ministro llegó al gobierno sin una fuente significativa de poder político. ${ }^{41}$

38 El PPC jugó un papel importante durante la campaña contra la revocatoria por su decisiva apuesta por el No, situación que le dejó réditos políticos importantes. Esta situación rompió una dinámica común en los procesos de revocatoria a nivel nacional, donde los perdedores de las elecciones son los principales promotores de este tipo de consulta popular (ver Puémape, 2013; Cameron y Sosa, 2013).

39 En el Perú se usan indistintamente los términos Presidente del Consejo de Ministros, Primer Ministro y Premier, para referirse al mismo cargo. Solo el primero está reconocido oficialmente en la Constitución.

40 Para profundizar sobre el Consejo de Ministros ver Awapara (2010). García y Toledo tuvieron, en sus cinco años de gobierno, cinco primeros ministros cada uno.

41 Esta situación que se confirmó con su salida a mediados de febrero del 2014, por un conflicto que se hizo evidente tras unas declaraciones de la primera dama y el Ministro de Economía desautorizando a Villanueva sobre el tema de la modificación del salario mínimo. Según sus propias declaraciones: "Yo tomo mis decisiones sobre hechos concretos, no sobre especulaciones ni sobre lo que sospecho (...) y este suceso se produjo cuando la señora (Nadine) Heredia opinó públicamente sobre un tema (el del salario mínimo) que correspondía al ámbito del Ejecutivo. (...) Allí decidí hablar con el Presidente y renunciar (...)”. “La primera dama tiene sus responsabilidades y límites. La mejor forma de apoyar al Presidente es que, en el gobierno, [ella] ayude con la institucionalización. Y que sus consejeros sean los propios ministros (...) Me imagino que (Luis) Castilla forma parte de un equipo que yo desconozco. Repito: he despachado y conversado con el Presidente. Igual con los ministros. En ninguna de esas circunstancias estuvo la señora Nadine" (El Comercio, 27/02/14). 


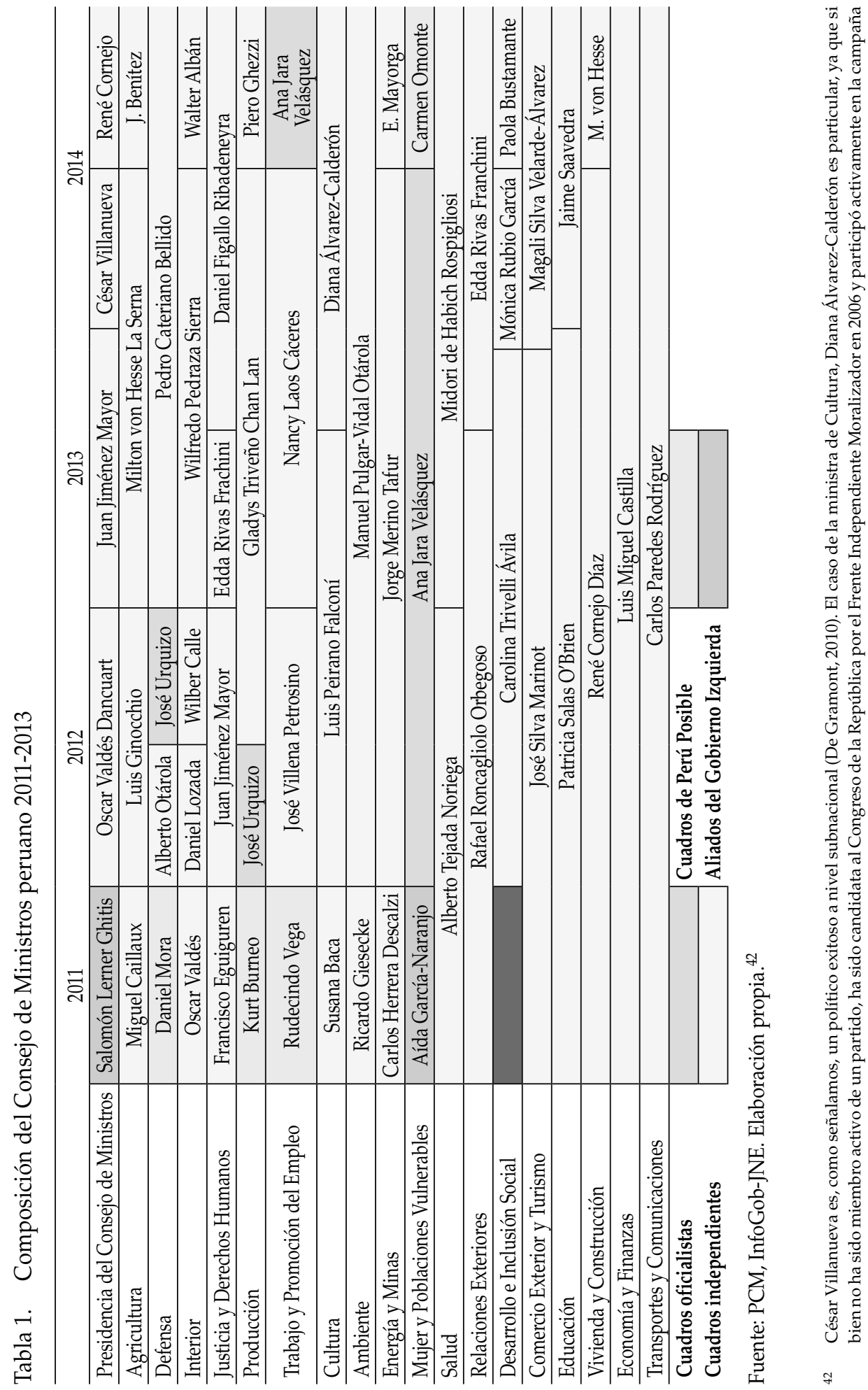


Esto nos lleva a una segunda característica del gobierno de Ollanta Humala, y que sí marca una diferencia con sus antecesores. Se trata de la importancia de la Primera Dama, Nadine Heredia, como poder fáctico al interior del gobierno. Se entiende que la Primera Dama no solo ejerce poder sobre el nombramiento y el desempeño de ciertos ministros, sino que además cuenta con un grupo de funcionarios adscritos a su "despacho" ${ }^{43} \mathrm{La}$ presencia de Heredia, y el poder que se le atribuye al interior del gobierno, han llevado a un alto interés por parte de la prensa y de otros actores políticos por conocer la posición política de la Primera Dama sobre los más diversos temas, en el entendido que se trata de una opinión con probables consecuencias políticas.

Junto a la figura de Heredia, destaca en el Poder Ejecutivo la presencia del ministro de economía Luis Castilla. Como ya hemos mencionado en la sección correspondiente a la marcha de la economía, la continuidad de Castilla en el gabinete resalta si se le compara con el alto nivel de rotación de los ministros en otros sectores (ver Tabla 1). Su continuidad es también signo del poder con que cuenta la tecnocracia económica en el Estado peruano. Del mismo modo en que se le atribuye a Heredia el control de ciertos sectores y ministros, sucede lo propio con Castilla. El Ministerio de Energía y Minas, un sector clave en el modelo de crecimiento económico peruano, sería uno de los que se encontrarían bajo su influencia.

Finalmente, un último hecho de trascendencia en el Ejecutivo que tuvo lugar en 2013 fue la salida del asesor presidencial en temas de seguridad, Adrián Villafuerte. Hasta el momento de su renuncia se consideraba a Villafuerte como una de las personas más cercanas al presidente Humala, además de ser uno de los poderes fácticos dentro del gobierno. Según información de la prensa peruana, Villafuerte ejercía una suerte de poder paralelo al de los ministros de Interior y Defensa, constituyéndose en un intermediario de facto entre Humala y los altos mandos militares y policiales. Su salida como resultado del ya mencionado escándalo López Meneses abre la posibilidad de que el nuevo Primer Ministro Villanueva tenga mayor margen de maniobra en estos sectores que con el que contaron sus antecesores. Precisamente se han anunciado reformas importantes en el sector Interior para el 2014.

\section{PODER LEGISLATIVO}

El Congreso de la República es el símbolo de la debilidad de las instituciones políticas peruanas, y es también una de las instituciones en las que se distinguen claramente las herencias del gobierno de Alberto Fujimori en nuestra democracia. Una primera y obvia herencia se encuentra en la estructura organizacional del Parlamento. ${ }^{44}$ Sin embar-

del FREDEMO (1990), siendo voceada por Mario Vargas Llosa como candidata al Parlamento, propuesta que finalmente rechazó (Vargas Llosa, 1993: 168).

43 Ver la compilación de denuncias y documentos en http://bit.ly/11TtCJ9 (Utero de Marita, 20/3/14).

44 El Congreso peruano es unicameral y cuenta con 130 congresistas, resultado de la reducción de su tamaño e importancia en la constitución de 1993. Un Congreso sólido y grande era visto no solo como innecesario desde la visión antipolítica del fujimorismo, sino que era además un obstáculo para la concentración del poder que caracterizó a ese gobierno (Degregori y Meléndez 2007: 47-53). 
go, una segunda herencia tiene que ver con la debilidad de los partidos, cuya crisis fue profundizada y favorecida por el gobierno de Fujimori (Degregori y Meléndez, 2007). Desde entonces, el escaso enraizamiento social y político con que cuentan los partidos hace que estos opten por conformar listas electorales basadas en figuras reconocidas en sus localidades o que cuentan con los recursos necesarios para solventar una campaña, pese a que no tengan vinculación previa con el partido político. Mientras que esta estrategia busca maximizar el número de votos que pueda alcanzar una agrupación durante las elecciones, ella se convierte en un problema inmediatamente después, cuando estos candidatos alcanzan posiciones de poder (Zavaleta, 2012).

Por un lado, los escándalos de pequeña corrupción y por mal uso del cargo de congresista son constantemente protagonizados por parlamentarios sin carrera política, y de cuya agenda política y económica poco conoce el partido que los llevó al cargo. Ello ha llevado a que el Congreso sea una de las instituciones políticas con menores niveles de aprobación ciudadana gobierno tras gobierno (ver Guibert y Cruz, 2013). Como se observa en el Gráfico 11, el 2013 no ha sido la excepción a la tendencia en la historia reciente del Parlamento. Debe resaltarse que, aunque las cifras sugieren un descenso desde agosto de 2011, el ascenso en la aprobación al Congreso se da con cada inicio de gobierno, solo para volver a sus niveles regulares (bajos) poco tiempo después. La marca explícita de la poca legitimidad del Congreso de la República se hizo evidente en la elección del Defensor del Pueblo, los miembros del Tribunal Constitucional y funcionarios del Banco Central de Reserva, episodio que generó una movilización urbana en rechazo de la denominada "repartija" de los cargos entre las principales fuerzas del Parlamento (ver Loaiza, 2013).

Por otro lado, la capacidad de los partidos para disciplinar a estos parlamentarios es muy escasa, con lo que el quiebre de bancadas ha sido la norma desde el retorno a la democracia. La configuración del Parlamento peruano no solo origina en los resultados

Gráfico 11: Aprobación comparada de los tres poderes del Estado

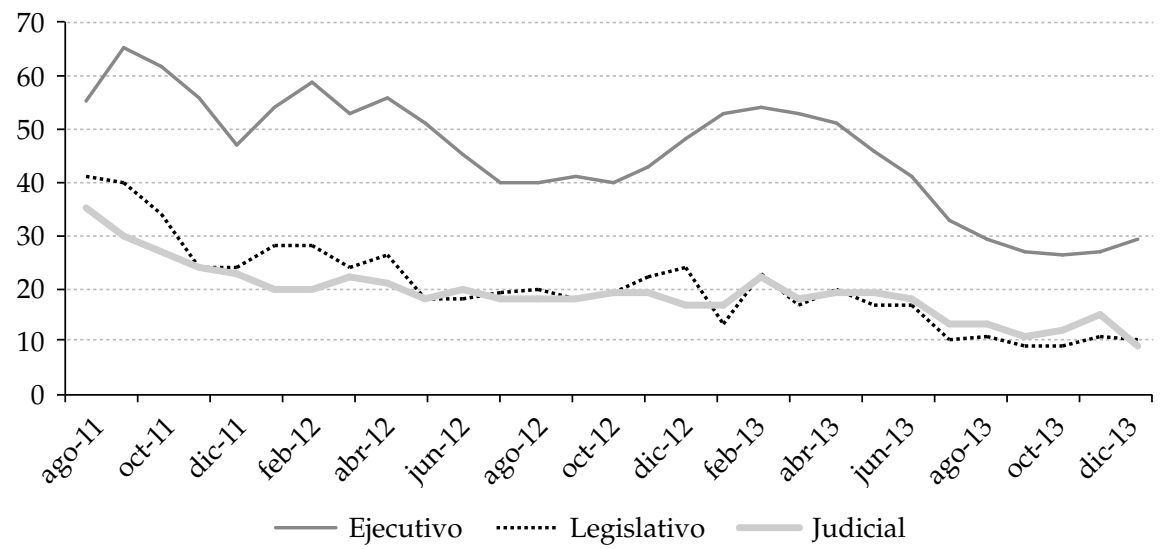

Fuente: Ipsos Perú. Elaboración propia. 
electorales, sino que se redefine en un proceso constante debido a la progresiva atomización de las coaliciones y la simbiosis entre sus fracciones (Valladares, 2010). Esta ha sido la tendencia en lo que va del gobierno de Ollanta Humala, y el 2013 no ha sido la excepción. Como se observa en la Tabla 2, el actual Congreso se inauguró con seis bancadas y cerró el 2013 con ocho.

La última escisión en el Parlamento se dio al interior de las bancadas de Alianza Parlamentaria y Alianza por el Gran Cambio (APGC). El primero de estos grupos estaba originalmente conformado por Perú Posible (el partido del expresidente Alejandro Toledo), Acción Popular (un partido tradicional peruano) y Somos Perú (un partido surgido durante los años noventa). Esta bancada era la más cercana colaboradora del oficialismo en el Parlamento, y representaba el espacio de centroderecha que le prestó su apoyo a Humala durante la segunda vuelta electoral de 2011. Por su parte, APGC era el grupo más heterogéneo del Congreso, y estaba conformado principalmente por el PPC, al que se agregaban parlamentarios de partidos pequeños. ${ }^{45}$

En total, ocho parlamentarios cambiaron de bancada en 2013. Cinco miembros de Alianza Parlamentaria y dos de APGC crearon la nueva bancada denominada "Unión Regional". Finalmente, un parlamentario adicional de APGC se integró a la bancada de Solidaridad Nacional. Los renunciantes a la bancada de Alianza Parlamentaria, todos miembros de Perú Posible, argumentaron distintas razones para su decisión. Sin embargo, la separación se dio en el contexto de graves denuncias periodísticas contra Alejandro Toledo y sus familiares, a quienes se acusa de realizar compras de inmuebles en Perú con dinero de procedencia desconocida. La división de este grupo parlamentario es el reflejo del debilitamiento de la imagen de Alejandro Toledo y de sus posibilidades políticas futuras. Finalmente, el Congreso no solo está marcado por divisiones, sino también por la sorpresiva continuidad de algunas bancadas como el fujimorismo, que ha mostrado cohesión como bancada parlamentaria desde el anterior periodo parlamentario en el que tampoco sufrieron ninguna división y se perfila como una de las bancadas más disciplinadas en el voto (Vela et al., 2014).

\section{EVALUACIÓN GENERAL SOBRE EL FUNCIONAMIENTO Y CALIDAD DE LA DEMOCRACIA}

Iniciamos este artículo señalando que el gobierno de Humala, incluido el 2013, era la expresión más reciente de una brecha entre Estado y sociedad que ha sido difícil de cerrar para todos los gobiernos democráticos que se sucedieron luego de la caída del gobierno de Alberto Fujimori. Esta democracia sin partidos (Tanaka, 2005; Levitsky y Cameron, 2003; Crabtree, 2010), en la que el descontento con las instituciones políticas se ha vuelto crónico, parece sostenerse hoy en el buen momento que atraviesa la economía peruana gracias al boom de las materias primas. Sería este buen momento el

45 Este grupo tuvo en común tan solo la candidatura de Pedro Pablo Kuczynski en 2011, por lo que la división de esta bancada era esperada desde el momento de su elección (ver Barrenechea, 2011). 


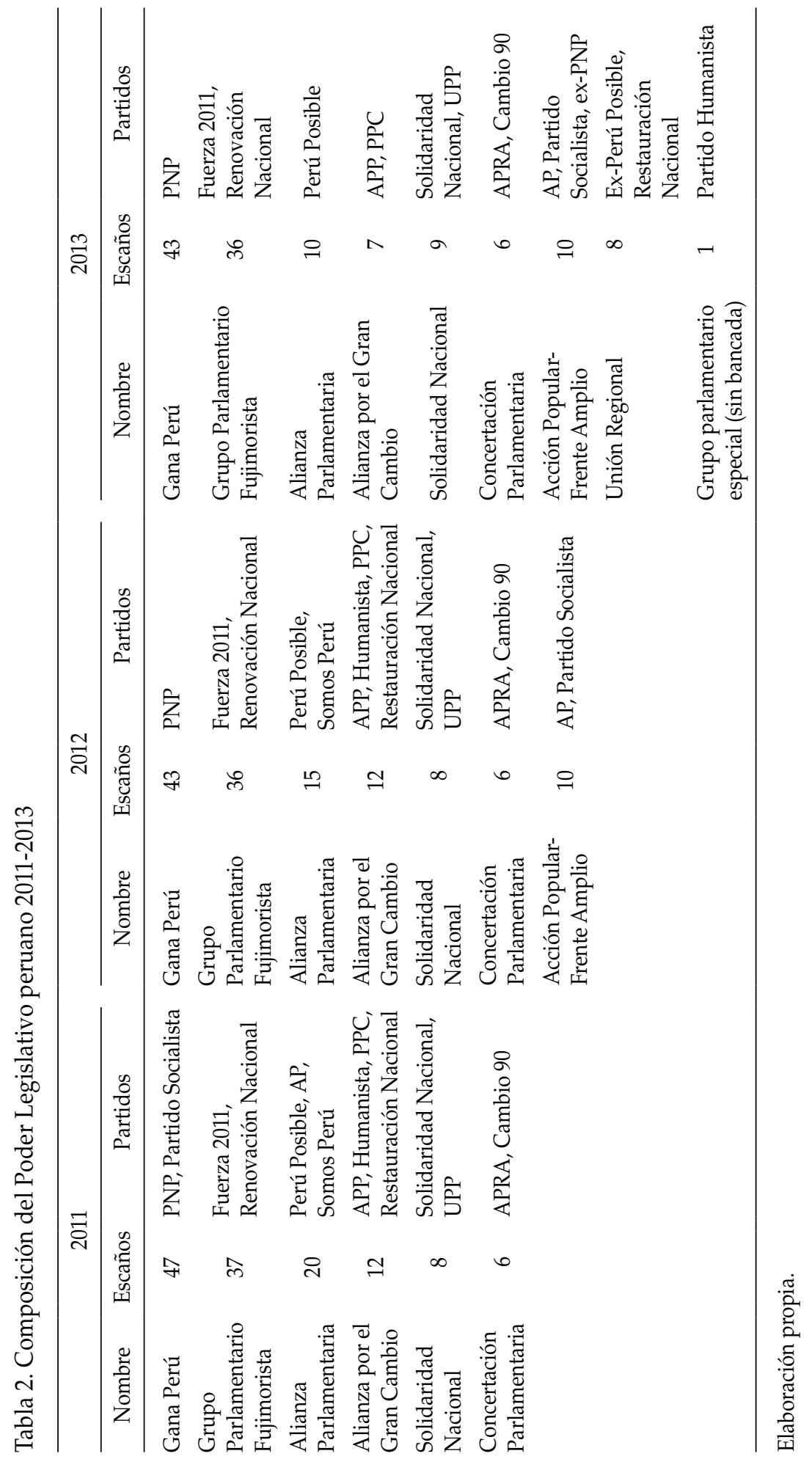


que evitaría una escalada mayor del descontento, que hoy se manifiesta principalmente en encuestas de opinión en las ciudades y en constantes pero inconexos episodios de movilización social en el campo. Sin instituciones sólidas para sostenerla, nuestra democracia parece subsistir gracias a la marea calma y al viento a favor de los que se han beneficiado este y otros gobiernos.

La democracia sin partidos, sin embargo, no parece contener la fórmula para su propia reforma. Por el contrario, el sistema tiende a reproducirse a sí mismo. Continuar en "piloto automático" puede traer más recompensas para los políticos que invertir en la construcción de instituciones políticas sólidas. Para conservar el poder, la fórmula consiste en mantener condiciones favorables a la inversión y ofrecerle certidumbre por el aislamiento de la tecnocracia económica (Dargent, 2008; Abusada et al., 2000). Si la clave de la relativa estabilidad peruana se encuentra más en su economía que en sus instituciones políticas, los incentivos para enfocarse en fortalecer a estas últimas no son demasiados.

El 2013 de Humala refleja claramente esta tendencia. Se han mantenido la estabilidad para la tecnocracia económica y las promisorias cifras de crecimiento económico, al mismo tiempo que se ha persistido en debilitar la figura del Primer Ministro y de cualquier otra agencia o espacio que implique la construcción de coaliciones sociales y políticas. De allí el debilitamiento del gobierno en el Congreso y la inestabilidad en el consejo de ministros. En este último espacio se tecnifican los sectores económicos y productivos, mientras que se desestima la importancia de una conducción política en el gabinete. Los primeros ministros son prescindibles, no así los ministros de economía. Se persiste en la fórmula de la riqueza económica y la pobreza política (ver Cotler, 2013).

En medio de este panorama, la única fuerza política nacional que parece estar en proceso de consolidación en esta democracia sin partidos es el fujimorismo. La importancia que adquirió el posible indulto a Alberto Fujimori y la sorprendente cohesión del fujimorismo en el Parlamento en dos periodos consecutivos hablan de la fortaleza de esta corriente política. Bajo el liderazgo de Keiko Fujimori el fujimorismo parece estar consolidando sus raíces en la sociedad peruana, al tiempo que avanza paulatinamente en su nivel de organización. Aunque esto está todavía por verse, se prevé que fujimorismo será el partido político nacional con mayor participación en las elecciones subnacionales del 2014.

Precisamente, el 2014 será un año electoral en que se definirán autoridades regionales y municipales. Este espacio puede abrir la posibilidad para una evaluación más amplia del proceso político peruano que incluya el nivel subnacional, con particular interés en la calidad de la democracia y en posibles nichos autoritarios a este nivel (Gibson, 2005); ${ }^{46}$ así como en el manejo que vienen haciendo estos gobiernos de los recursos económicos extraordinarios provenientes de las industrias extractivas (ver Crabtree, 2013).

46 Especialmente a partir del caso de autoritarismo subnacional que parece perfilarse en el gobierno regional de Ancash que, como ha señalado Steven Levitsky, cumple con las características de un autoritarismo contemporáneo: espionaje telefónico, compra de periodistas y líneas editoriales locales, denuncias de corrupción y compra de funcionarios en el Poder Judicial, así como el acoso a opositores mediante amenazas de muerte (Cardoza, 2014). 
Sin consolidar instituciones, la democracia peruana parece hoy encontrarse en medio de un ciclo de precaria continuidad. Su viabilidad en el largo plazo en estas condiciones es una incógnita. La respuesta probablemente llegará cuando el viento deje de soplar a favor y se tenga que abandonar el "piloto automático".

\section{REFERENCIAS}

Abusada, Roberto et al. 2000 (ed.) La reforma inconclusa: rescatando los noventa. Lima: Instituto Peruano de Economía.

Alza, Carlos. 2012. Estudio sobre la evolución de la política del servicio civil peruano durante los últimos 30 años (1980-2011) para la Autoridad Nacional del Servicio Civil - SERVIR. Lima: Presidencia del Consejo de Ministros.

Aramburú, Carlos. 2013. “Políticas sociales: ¿dónde estamos y qué falta?". Revista Argumentos 7 (5): 25-30. Aragón, Jorge y Rodrigo Barrenechea. 2012. “Entrevista a Julio Cotler: Todavía somos una sociedad postFujimori". Revista Argumentos 6 (1): 1-5.

Arce, Moisés. 2010. El fujimorismo y la reforma del mercado en la sociedad peruana. Lima: Instituto de Estudios Peruanos.

Arce, Moisés. 2014. Resource Abundance and Protest: Peru in Comparative Perspective. Pennsylvania: University of Pittsburgh Press.

Awapara, Omar. 2010. "Despacio se llega lejos: cambio institucional e instituciones latentes. El caso de la Presidencia del Consejo de Ministros". Revista Apuntes 67: 5-36.

Barrenechea, Rodrigo. 2011. "El Sancochado: El pragmatismo de las alianzas sin partidos". En Anticandidatos: Guía analítica para unas elecciones sin partidos, Carlos Meléndez (comp.), 149-170. Lima: Mitin.

Bebbington, Anthony. 2013 (ed.). Industrias extractivas. Lima: Instituto de Estudios Peruanos, Propuesta Ciudadana y Centro de Estudios Políticos, Económicos y Sociales.

Bedoya, César. 2013. "La nueva propuesta del Estado para el abordaje de conflictos sociales: la Oficina Nacional de Diálogo y Sostenibilidad". Revista Argumentos 7 (1): 10-13.

Bregaglio, Renata, Carmela Chávez y Rosa Arévalo. 2013. Programas Sociales y Derecho a la Alimentación en el Perú: El Análisis del Programa Nacional de Alimentación Escolar Qali Warma desde un enfoque basado en derechos humanos. Lima: Instituto de Democracia y Derechos Humanos de la Pontificia Universidad Católica del Perú.

Cameron, Maxwell A. y Paolo Sosa. 2013. "Organizaciones políticas no institucionalizadas y Estado de Derecho en el Perú post-Fujimori: Una propuesta para la investigación". Politai. Revista de Ciencia Política 4 (7): 89-106.

Cardoza, Patricia. 2014. "Steven Levitsky: Ancash tiene todos los elementos de un autoritarismo contemporáneo". Diario Correo de Chimbote, 24 de marzo.

Contreras, Carlos, Maritza Paredes y Rosemary Thorp. 2011. "El enraizamiento de la desigualdad regional y sus consecuencias para las desigualdades de grupo: de la década de 1890 a la de 1960". En La etnicidad y la persistencia de la desigualdad, Rosemary Thorp y Maritza Paredes, 139-140. Lima: Instituto de Estudios Peruanos.

Correa, Norma y Terry Roopnaraine. 2013. Pueblos indígenas y programas de transferencias condicionadas. Lima: Pontificia Universidad Católica del Perú, Banco Interamericano de Desarrollo.

Cotler, Julio. 2013. "Las paradojas de la democracia peruana". En Miradas cruzadas: políticas públicas y desarrollo regional en Perú, Bruno Revesz (ed.), 55-88. Lima: Instituto de Estudios Peruanos.

Crabtree, John. 2010. "Democracy without Parties? Some Lessons from Peru". Journal of Latin American Studies 42 (2): 357-382.

Crabtree, John. 2013. Uso y abuso del sistema del canon en el gobierno regional del Cusco. Lima: Grupo Propuesta Ciudadana y Centro Bartolomé de las Casas.

Dargent, Eduardo. 2008. Islas de eficiencia y reforma del Estado: Ministerios de Economía y Salud 1990-2008. Lima: Consorcio de Investigación Económica y Social. 
Dargent, Eduardo. 2013. "Estado, política y sociedad durante el boom de los commodities". Revista Argumentos 7 (5): 66-75.

Dargent, Eduardo y Paula Muñoz. 2012. "Perú 2011: Continuidades y cambios en una democracia sin partidos". Revista de Ciencia Política 32 (1): 245-268.

De Gramont, Diane. 2010. “¿Se está quedando Lima detrás? Las elecciones regionales de noviembre de 2006 y el ascenso de los movimientos regionales en el Perú". Politai. Revista de Ciencia Política 1 (1): 56-73.

Degregori, Carlos et al. 1996. Las rondas campesinas y la derrota de Sendero Luminoso. Lima: Instituto de Estudios Peruanos y Universidad Nacional San Cristóbal de Huamanga.

Degregori, Carlos y Carlos Meléndez. 2007. El nacimiento de los otorongos. El Congreso de la República durante los gobiernos de Alberto Fujimori (1990-2000). Lima: Instituto de Estudios Peruanos.

Esparch, Nuria. 2012. Ventanas de oportunidad: el caso de la reforma del Servicio Civil. Lima: Grupo de Análisis para el Desarrollo.

Gálvez, Álvaro y Paolo Sosa. 2013. "'El problema del indio': una mirada a la implementación de la consulta previa desde la lógica del Estado y sus funcionarios". Revista Argumentos 7 (5): 7-15.

Ghezzi, Piero y José Gallardo. 2013. ¿Qué se puede hacer con el Perú? Ideas para sostener el crecimiento económico en el largo plazo. Lima: Universidad del Pacífico y Fondo Editorial de la Pontificia Universidad Católica del Perú.

Gibson, Edward. 2005. "Boundary Control: Subnational Authoritarianism in Democratic Countries". World Politics 58 (1): 101-132.

Grompone, Álvaro. 2013. “Entre la estabilidad y la intrascendencia: las políticas económicas de la primera mitad del gobierno de Ollanta Humala". Revista Argumentos 7 (5): 37-46.

Guibert, Yamilé y Marilia Cruz. 2013. Determinantes de la confianza en el Congreso del Perú. Cuaderno de Investigación $N^{\circ}$ 2. Lima: Instituto de Opinión Pública de la Pontificia Universidad Católica del Perú.

International Court of Justice. 2014. Judgement: Maritime Dispute (Peru v. Chile). En línea: http:/ /www. icj-cij.org/docket/ files/137/17930.pdf

Latinobarómetro. 2013. Informe 2013. Santiago de Chile: Corporación Latinobarómetro.

Levitsky, Steven y Maxwell A. Cameron. 2003. "Democracy without Parties? Political Parties and Regime Change in Fujimori's Peru". Latin American Politics and Society 45 (3): 1-33.

Loaiza, Pamela. 2013. "Los orígenes de la repartija. Balance de la selección de magistrados del Tribunal Constitucional". Revista Argumentos 7 (4): 9-10.

Maldonado, Arturo. 2013. "Racionalidad y emotividad en las elecciones peruanas: una propuesta de investigación". Revista Argumentos 7 (1): 44-49.

Meléndez, Carlos. 2011. "Perder es cuestión de método. Lecciones del fracaso electoral de Luis Castañeda Lossio". En Post Candidatos: Guía analitica de supervivencia hasta las próximas elecciones, Carlos Meléndez (comp.), 176-196. Lima: Mitin.

Meléndez, Carlos. 2012a. Partidos inesperados: la institucionalización del sistema de partidos en un escenario postcolapso partidario. Perú 2001-2011. Documento de Trabajo. Lima: Friedrich Ebert Stiftung.

Meléndez, Carlos. 2012b. La soledad de la política: Transformaciones estructurales, intermediación política y conflictos sociales en el Perú (2000-2012). Lima: Mitin.

Meléndez, Carlos y Carlos León. 2010. "Perú 2009: Los legados del autoritarismo". Revista de Ciencia Política 30 (2): 451-477.

Meléndez, Carlos y Paolo Sosa. 2013. "Perú 2012: ¿Atrapados por la historia?". Revista de Ciencia Política 33 (1): 325-350.

Mora, Daniel et al. 2001. Las Fuerzas Armadas en la transición democrática en el Perú. Lima: Instituto de Estudios Peruanos.

Murakami, Yusuke. 2013. “Desigualdad, conflictos sociales y el proceso electoral de 2011 en el Perú". En América Latina en la era posneoliberal: democracia, conflictos y desigualdad, Yusuke Murakami (ed.), 177218. Lima: Instituto de Estudios Peruanos y Center for Integrated Area Studies, Kyoto University.

Navarro, Moisés. 2013. “La política del diálogo". Revista Poder 55: 18-26.

Paredes, Maritza. 2010. "En una arena hostil. La politización de lo indígena en el Perú". En La iniciación de la política. El Perú político en perspectiva comparada, Alberto Vergara y Carlos Meléndez (eds.). Lima: Fondo Editorial de la Pontificia Universidad Católica del Perú. 
Puémape, Félix. 2013. “¿Imposibilidad o error estratégico? La poca competitividad electoral de los partidos políticos peruanos en la última década". Politai. Revista de Ciencia Política 4 (7): 119-132.

Rospigliosi, Fernando. 2013. "Seguridad ciudadana: deterioro sin pausa". Revista Argumentos 7 (5): 31-36.

SERVIR. 2012. El servicio civil peruano: Antecedentes, marco normativo actual y desafíos para la reforma. Lima: Presidencia del Consejo de Ministros.

Tanaka, Martín. 2005. Democracia sin partidos. Perú 2000-2005. Los problemas de representación y las propuestas de reforma politica. Lima: Instituto de Estudios Peruanos.

Tanaka, Martín y Sofía Vera. 2007. "Perú: Entre los sobresaltos electorales y la agenda pendiente de la exclusión". Revista de Ciencia Política, volumen especial: 235-247.

Trivelli, Carolina. 2014. "Juntos y lo productivo". Revista Poder 59: 10.

Valladares, Jorge. 2010. "Representación, competencia y unidad en el Congreso peruano". En La iniciación de la política. El Perú político en perspectiva comparada, Alberto Vergara y Carlos Meléndez (eds.). Lima: Fondo Editorial de la Pontificia Universidad Católica del Perú.

Vargas Llosa, Mario. 1993. El pez en el agua. Memorias. Barcelona: Editorial Seix-Barral.

Vela, Estelí et al. 2014. "La disciplina y efectividad de las bancadas de oposición en el Parlamento en los casos de las Interpelaciones durante los gobiernos de Toledo, García y Humala (2001-2013)". Politai. Revista de Ciencia Política 5 (8), en prensa.

Vergara, Alberto. 2013. Ciudadanos sin República ¿Cómo sobrevivir a la jungla política peruana? Lima: Editorial Planeta.

Zavaleta, Mauricio. 2013. “Las fuerzas gravitacionales de la descentralización: Historia de tres elecciones subnacionales". Revista Argumentos 7 (2): 17-25.

Rodrigo Barrenechea es estudiante en el programa de doctorado en ciencia política de Northwestern University, Estados Unidos, en la especialidad de Política Comparada. Obtuvo su título de pregrado en sociología en la Pontificia Universidad Católica del Perú (PUCP) y se desempeñó como investigador del Instituto de Estudios Peruanos (IEP). E-mail: rbarrenechea@u.northwestern.edu

Paolo Sosa Villagarcía es politólogo de la Pontificia Universidad Católica del Perú (PUCP). Actualmente se desempeña como predocente en esa casa de estudios y como asistente de investigación en el Instituto de Estudios Peruanos (IEP). E-mail: psosa@iep.org.pe 